\title{
REVIEW
}

\section{Protein biomarkers in cystic fibrosis research: where next?}

\author{
Sally H Pattison and J Stuart Elborn*
}

\begin{abstract}
Cystic fibrosis is one of the most common life-limiting inherited disorders. Its clinical impact manifests chiefly in the lung, pancreas, gastrointestinal tract and sweat glands, with lung disease typically being most detrimental to health. The median age for survival has increased dramatically over the past decades, largely thanks to advances in understanding of the mechanisms and consequences of disease, leading to the development of better therapies and treatment regimes. The discovery of dysregulated protein biomarkers linked to cystic fibrosis has contributed considerably to this end. This article outlines clinical trials targeting known protein biomarkers, and the current and future contributions of proteomic techniques to cystic fibrosis research. The treatments described range from those designed to provide functional copies of the mutant protein responsible for cystic fibrosis, to others addressing the associated symptoms of chronic inflammation. Preclinical research has employed proteomics to help elucidate pathways and processes implicated in disease that might present opportunities for therapy or prognosis. Global analyses of cystic fibrosis have detected the differential expression of proteins involved in inflammation, proteolytic activity and oxidative stress, which are recognized symptoms of the cystic fibrosis phenotype. The dysregulation of other processes, such as the complement and mitochondrial systems, has also been implicated. A number of studies have focused specifically on proteins that interact with the cystic fibrosis protein, with the goal of restoring its normal proteostasis. Consequently, proteins involved in synthesis, folding, degradation, translocation and localization of the protein have been identified as potential therapeutic targets. Cystic fibrosis patients are prone to lung infections that are thought to contribute to chronic inflammation, and thus proteomic studies have also searched for microbiological biomarkers to use in early infection diagnosis or as indicators of virulence. The review concludes by proposing a future role for proteomics in the high-throughput validation of protein biomarkers under consideration as outcome measures for use in clinical trials and routine disease monitoring.
\end{abstract}

\section{Cystic fibrosis pathophysiology}

Cystic fibrosis (CF) is a recessive disorder caused by mutations to the gene encoding the cystic fibrosis transmembrane conductance regulator $(C F T R)$, a chloride channel responsible for directing the movement of salt and water in and out of cells. To date, over 1,700 mutations of this gene [1], categorized into six classes according to their functional effects [2], have been linked to CF. F508del is the most common mutation and accounts for $70 \%$ of CF in most Caucasian populations [3].

The reduction of CFTR activity perturbs normal water and salt balance, resulting in the production of unusually thick, sticky mucus at tissue surfaces. This reduction in

*Correspondence: s.elborn@qub.ac.uk

Centre for Infection and Immunity, Queen's University Belfast, Belfast BT9 7BL, Northern Ireland, UK surface fluid in the lung promotes persistent and recurrent infections by impeding the mucociliary clearance of invading microbes [4], and in the digestive tract by hindering the movement of feces, which may cause bowel obstruction. Mucus plugging in the glands may block ducts, leading to tissue scarring and loss of function. In particular, ductal plugging of the pancreas prevents the production of sufficient digestive enzymes for effective nutrition.

\section{Protein targets in current CF clinical trials}

Following the cloning of the CF gene in 1989 [5] and the subsequent introduction of DNA-based disease diagnosis, the focus of protein target discovery shifted towards the identification of candidate drug targets and indicators of disease severity and/or response to treatment. Restoration of normal CFTR function is the chief therapeutic goal as this will address the underlying cause of CF disease rather than just treat the symptoms. Gene 
therapy trials are underway aiming to deliver functional CFTR genes to the epithelial cells of the CF airway. In phase 1, treatment with aerosolized compacted DNA nanoparticles containing the CFTR gene (Copernicus Therapeutics, Cleveland, Ohio, USA) induced nasal chloride current changes in CF patients, suggesting increased CFTR functionality, but gene expression was not detected [6]. The UK Cystic Fibrosis Gene Therapy Consortium [7] is currently performing a phase $1 / 2$ safety study using pGM169/GL67A [8] and will proceed to a multidose study in July 2011. This system utilizes liposomes to promote the aerosolized delivery of a DNA plasmid containing the CFTR gene.

Two drugs from Vertex Pharmaceuticals (Abingdon, UK), VX-770 and VX-809, aiming to promote the activity of mutant CFTR by increasing channel opening and trafficking to the membrane, respectively, are currently in clinical trials [6]. In phase 2, VX-770 improved measures of CFTR function such as nasal potential difference and sweat chloride concentration [6]. Ataluren (formerly PTC124; PTC Therapeutics, South Plainfield, New Jersey, USA), which is designed to increase synthesis of fulllength functional CFTR, improved CFTR function for some patients in phase 2 trials [9] and is currently in phase 3 [6]. Sildenafil, which corrects F508del-CFTR trafficking and increased chloride transport in F508del-CFTR mice [10], is the subject of phase $1 / 2$ clinical trials [8].

Lung disease, resulting from chronic infection and inflammation, is the most common cause of death in the CF population and thus its treatment is a key goal of CF therapy. In the CF lung, activation of the nuclear factor (NF)-KB signaling pathway leads to enhanced production of pro-inflammatory mediators, including interleukin (IL)-8. IL-8 is a potent neutrophil chemoattractant resulting in neutrophil recruitment and accompanying tissue damage through the release of neutrophil proteases and reactive oxygen species. Drugs are being developed to treat various proteins involved in this inflammatory cycle. Digitoxin has been shown to suppress hypersecretion of pro-inflammatory IL-8 by CF lung epithelial cells in vitro [11] and its effect on sputum IL-8 and neutrophil counts is currently being assessed in a phase 2 clinical trial (ClinicalTrials.gov Identifier: NCT00782288 [8]). GSK SB 656933 (GlaxoSmithKline, Uxbridge, UK) is an antagonist of the neutrophil IL-8 receptor CXCR2, which mediates neutrophil migration. It has demonstrated safety in a phase 1 trial [6] and is now being evaluated in a phase 2 study (ClinicalTrials.gov Identifier: NCT00903201 [8]) for pharmacodynamics and efficacy, including the reduction of sputum neutrophil elastase and neutrophil counts. Pioglitazone, already approved for treatment of other clinical conditions, is being assessed for safety and anti-inflammatory action in phase 1 clinical trials against $\mathrm{CF}$ lung disease [6]. Its target, peroxisome proliferator-activated receptor $\gamma$, which is reduced in CF [12], exerts an anti-inflammatory effect by negatively regulating NF- $\mathrm{kB}$ activation [13]. The sputum protease matrix metalloproteinase- 9 has also been linked to poor lung function and airway inflammation in CF children [14] and its activity is being targeted by the antibiotic doxycycline in a current trial (ClinicalTrials.gov Identifier: NCT01112059 [8]).

Various proteins and protein degradation products have been explored as candidate biomarkers of clinical outcome, such as neutrophil elastase and IL-8 [15], degradation of lung surfactant protein SP-A [16], urinary desmosine [17] and proline-glycine-proline [18]. However, as yet, none of these markers has been proven sufficiently robust for routine adoption in clinical trials [19].

\section{Proteomic contributions to CF research}

Preclinical medical research is increasingly adopting a systems rather than a reductionist approach to understanding and treating disease, with clinical proteomics contributing to the characterization and measurement of pathophysiological stages. Proteomic-based CF research has employed techniques such as two-dimensional gel electrophoresis (2-DE), liquid chromatography, mass spectrometry (MS) and antibody/protein microarrays to analyze secretions, cells and whole tissues from in vitro or in vivo disease models, human subjects and infecting micro-organisms. Laser capture microdissection, cell fractionation and co-immunoprecipitation have been used to limit analyses to the sub-proteomes of interest.

Global comparative analyses of $\mathrm{CF}$ versus non-CF samples have been used to identify differentially expressed proteins in human bronchoalveolar lavage fluid (BALF) [20,21], sputum [22], bronchial biopsy tissue [23], serum [24] and cultured epithelial cells [25,26], and in mouse lung and colonic tissue [27-29]. Many of the proteins highlighted by global analyses can be related functionally to biological processes and pathways known to contribute to CF disease pathogenesis, including chronic inflammation, proteolytic activity and oxidative stress response proteins.

Chronic neutrophil-mediated inflammation typifies the $\mathrm{CF}$ lung, and comparative proteomic studies have provided data to support and improve our understanding of the mechanisms involved. Srivastava et al. [24] have detected in CF serum differential levels of proteins belonging to the NF-kB pathway, which is known to enhance production of inflammatory mediators, while Sloane et al. [30] have found that sputum from adults with CF is characterized by inflammation-related proteins, including increased production of IL-8. Neutrophil proteins, including $\alpha$-defensins and $S 100$ proteins, have been shown to be differentially expressed in CF BALF [31] and sputum [22]. Also, lower levels of anti-inflammatory 
proteins Clara cell secretory protein [22] and annexin A1 [29] have been observed in CF nasal epithelial cells and sputum, respectively. Additionally, the absence of annexin A1 has been associated with upregulation of the proinflammatory cytosolic phospholipase A2 in the colonic crypts of CF mice [29].

Chronic inflammation of the CF lung is thought to induce the overexpression of proteases, thus perturbing the protease/anti-protease balance and resulting in tissue damage and disease. Through the application of shotgun proteomic methods, Gharib et al. [20] detected increased levels of 22 proteases and peptidases in human CF BALF, including neutrophil elastase, cathepsin $\mathrm{G}$ and proteinase 3. They also identified increased expression of human monocyte/neutrophil elastase inhibitor [20], which when applied as an aerosolized treatment to rats has been shown to reduce inflammation [32]. Extensive proteolytic degradation, including truncation of the anti-protease $\alpha_{1}-$ antitrypsin and degradation of IgG, has been observed in CF sputum [30].

High levels of toxic reactive oxygen species and oxidative stress are characteristic of the CF lung. Reduced glutathione, which acts as an antioxidant and in detoxification, has been observed at a lower level in CF lung lavage fluid [33]. In support of this finding, Roxo-Rosa et al. [26] have detected, via 2-DE comparative proteomics of $\mathrm{CF}$ and non-CF mouse nasal epithelial cells, reductions in the levels of glutathione-related proteins: glutathione $S$-transferase, which catalyses the glutathione-mediated detoxification of oxidative stress products; peroxiredoxin 6, a glutathione-dependent peroxidase involved in defense against oxidative stress; and Hsp27, a heat shock protein that can increase intracellular levels of glutathione and acts as a chaperone for detoxification. Other proteomic studies have identified differential expression of myeloperoxidase, superoxide dismutase, catalase and glutathione reductase in CF BALF [20], and increased levels of myeloperoxidase in CF sputum [30]. Together these data help elucidate mechanisms that are likely to contribute to oxidative stress in the CF lung.

Other biological processes and proteins where functional links to CF disease are less well established or absent have also been implicated by global comparative proteomics. Differential expression of mitochondrial proteins has been reported in human CF nasal epithelial cells [26] and bronchial tissue [23], implicating a CFassociated reduction in mitochondrial metabolism, and the recent mapping of the CF BALF proteome [20] has implicated dysregulation of the complement system as a novel CF phenotype that may impact lung disease pathogenesis by impairing response to chronic infections. Investigation of the response of murine $\mathrm{CF}$ airway epithelial cells to injury detected reductions in enzymes involved in prostaglandin and retinoic acid metabolism; this implicates these pathways in the CF abnormal injury response, although no functional role has been determined.

More focused comparative proteomic studies have concentrated on specific protein subgroups, such as those involved in pathways of interest or executing certain roles. An investigation by Chen et al. [34] of the mechanisms triggering the overproduction of cytokines IL-6 and IL-8, associated with excessive CF lung inflammation, identified a regulatory pathway that is significantly reduced in CF. Moreover, they demonstrated that correction of the pathway reduced IL- 6 and IL-8 production [34]. Individual protein families have also been studied, such as lung surfactant proteins and mucins, both of which are involved in pathogen clearance from the airways. The structural modification of lung surfactant proteins SP-A and SP-D [35] and degradation of mucins MUC5B and MUC5AC [36] have been detected in CF BALF and sputum, respectively, and are thought to be relevant to lung disease. Additionally, mucin glycosylation has been highlighted as a possible predictor of lung condition [36].

Particular attention has been directed towards identifying proteins that interact with CFTR with the goal of understanding and restoring normal CFTR proteostasis through the correction of CFTR synthesis, folding, aggregation, degradation, trafficking and stable localization. F508del, the most common mutation of the CFTR gene, gives rise to incorrectly folded CFTR that is translocated from the endoplasmic reticulum to the cytosol for proteosomal degradation. An investigation by Goldstein et al. [37] of proteins that co-precipitate with F508del-CFTR has identified interaction with valosincontaining protein (VCP)/p9, a component of the translocation machinery, as being associated with inefficient processing of the mutant CFTR. Gomes-Alves et al. [38] used 2-DE to compare protein profiles of cell lines expressing wild-type or F508del-CFTR at $37^{\circ} \mathrm{C}$ and $26^{\circ} \mathrm{C}$, and have identified mechanisms, including the induction of the unfolded protein response and downregulation of degradative proteins, which may contribute to the coldshock-induced rescue of F508del-CFTR. By comparing the CFTR interactomes of bronchial epithelial cells expressing chemically and genetically repaired F508delCFTR, Singh et al. [39] identified a set of Hsp70 family proteins as implicated in rescue of the mutant protein. Additionally, Wang et al. [40] showed the importance of Hsp60 co-chaperones in CFTR folding and demonstrated rescue of F508del-CFTR by partial small interfering RNA silencing of the Hsp60 co-chaperone Aha1. Understanding the mechanisms that can contribute to F508del-CFTR rescue may suggest potential therapeutic targets. Also, study of the CFTR interactome has led to elucidation of the molecular defect of S13F-CFTR [41] as relating to defective interaction with filamins, which 
anchor plasma membrane CFTR to the actin cytoskeleton [41].

Repeated or chronic microbial infection is thought to be a major contributor to the excessive inflammation that precipitates CF lung damage, and a variety of proteomic approaches have been exploited to discover bacterial antigenic biomarkers that could provide potential candidates for infection diagnosis, prognosis indicators or vaccine development. Pedersen et al. [42] used a novel enrichment technique employing CF patient antibodies as capture ligands prior to proteomic analysis to enhance the identification of Pseudomonas aeruginosa antigens. The antigens detected by this method included stress, immunosuppressive and alginate synthetase pathway proteins. Using proteomic analysis of non-enriched serum samples from CF patients with different stages of infection, Rao et al. [43] identified outer membrane protein OprL as associated with initial P. aeruginosa infection and thus proposed serum reactivity to OprL as an early diagnostic. Montor et al. [44] generated protein microarrays displaying all predicted outer membrane and exported proteins expressed by $P$. aeruginosa reference strain PAO1 and used these to interrogate serum samples from CF patients infected with $P$. aeruginosa. They identified 48 antigenic proteins, 12 of which were common to approximately $50 \%$ of the samples. Alternatively, whole cell MS has been proposed for the rapid identification of commonly misidentified bacterial species [45].

Proteomics has helped elucidate factors pertinent to virulence, adaptation and in vivo survival of the pathogen P. aeruginosa [46-49], which is particularly indicative of a poor prognosis [50]. These may present candidate drug targets for treatment of CF infections. The quorum sensing intercellular communication systems have received particular attention as they largely coordinate bacterial virulence $[51,52]$.

\section{The future potential of proteomics}

The constant advance of proteomic strategies, instrumentation and data analysis provides an ever-increasing set of tools available for expanding CF research. Two strands for future studies are envisaged: the continuing investigation of disease pathology aiming to discover prognostic, diagnostic and therapeutic biomarkers; and the translation of existing knowledge into clinical applications of benefit to the CF population. The recent drift from traditional 2-DE to gel-free methods for protein and peptide separation is still under-represented in CF biomarker discovery, although their potential for extending shotgun (that is, global) proteome coverage has already been demonstrated for BALF. By complementing traditional gel separation of proteins with the twodimensional liquid chromatography separation of tryptic digests, Guo et al. [53] were able to improve the number of proteins detected in mouse BALF from 212 to 297, although they noted that their methods did not permit quantitative analyses. More recently, Gharib et al. [20] used quantitative shotgun proteomics to compare human CF and non-CF BALF from 12 subjects, and were able to distinguish the differential expression of hundreds of proteins, including those involved in pathways implicated in CF pathophysiology. Wider adoption of these approaches will enable protein detection over a larger dynamic range, thus including in the pool of potential biomarkers proteins of lower abundance that could not be detected using traditional proteomic techniques. Future biomarker discovery will also greatly benefit from the recent generation of pigs with mutated CFTR genes [54,55], which provides a model that more closely resembles human disease than current mouse models, and thus enables further investigation of biomarkers relevant to long-term disease progression and treatment efficacy.

The major shortfall in current proteomics research is the gap between the discovery of biomarkers and their clinical application. One hindrance has been the lack of tools for high-throughput validation. Advances in MS selected reaction monitoring have enabled the concurrent measurement of multiple researcher-designated proteins in a sample and may in future bypass the need for the development of a separate antibody-based assay for each individual proteins to be quantified [56]. This increases the feasibility of assaying large sample numbers with sufficiently high specificity and sensitivity to enable the simultaneous statistical validation of multiple candidate biomarkers [57]. The validation of a panel of CFspecific protein biomarkers could precipitate the production of novel biomarker arrays or tests for individual proteins. Such tools would permit the quantification of new outcome measures for assessing disease progression and/or response to treatment in clinical trials, and may be applicable to future routine clinical practice [58].

\section{Conclusions}

Proteins and their interactions ultimately steer CF disease, making their study invaluable for improving our understanding of pathophysiology and potential treatment opportunities. Considerable knowledge has been gained so far by the application of proteomics to $\mathrm{CF}$ research and rapid advancements in this field are expected to augment its future contribution towards improving the prognosis of CF patients.

\section{Abbreviations}

BALF, bronchoalveolar lavage fluid; CF, cystic fibrosis; CFTR, cystic

fibrosis transmembrane conductance regulator; 2-DE, two-dimensional electrophoresis; IL, interleukin; MS, mass spectrometry; NF, nuclear factor.

Competing interests

The authors declare that they have no competing interests. 


\section{Authors' contributions}

SHP and JSE drafted and approved the manuscript.

Published: 16 December 2010

\section{References}

1. Cystic Fibrosis Mutation Database [http://www.genet.sickkids.on.ca/cttr]

2. Ratjen FA: Cystic fibrosis: pathogenesis and future treatment strategies. Respir Care 2009, 54:595-605.

3. Cystic Fibrosis Genetic Analysis Consortium: Worldwide survey of the delta F508 mutation - report from the cystic fibrosis genetic analysis consortium. Am J Hum Genet 1990, 47:354-359.

4. Boucher R: Evidence for airway surface dehydration as the initiating event in CF airway disease. J Intern Med 2007;261:5-16.

5. Riordan J, Rommens J, Kerem B, Alon N, Rozmahel R, Grzelczak Z, Zielenski J, Lok S, Plavsic N, Chou J: Identification of the cystic fibrosis gene: cloning and characterization of complementary DNA. Science 1989, 245:1066-1073.

6. Cystic Fibrosis Foundation [http://www.cff.org]

7. The UK Cystic Fibrosis Gene Therapy Consortium [http://www. cfgenetherapy.org.uk]

8. ClinicalTrials.gov [http://www.clinicaltrials.gov]

9. Kerem E, Hirawat S, Armoni S, Yaakov Y, Shoseyov D, Cohen M, Nissim-Rafinia M, Blau H, Rivlin J, Aviram M, Elfring GL, Northcutt VJ, Miller LL, Kerem B, Wilschanski M: Effectiveness of PTC124 treatment of cystic fibrosis caused by nonsense mutations: a prospective phase II trial. Lancet 2008, 372:719-727.

10. Lubamba B, Lecourt H, Lebacq J, Lebecque P, De Jonge H, Wallemacq P, Leal $\mathrm{T}$ : Preclinical evidence that sildenafil and vardenafil activate chloride transport in cystic fibrosis. Am J Respir Crit Care Med 2008, 177:506-515.

11. Srivastava M, Eidelman O, Zhang J, Paweletz C, Caohuy H, Yang Q, Jacobson KA, Heldman E, Huang W, Jozwik C, Pollard BS, Pollard HB: Digitoxin mimics gene therapy with CFTR and suppresses hypersecretion of IL-8 from cystic fibrosis lung epithelial cells. Proc Natl Acad Sci U S A 101:7693-7698.

12. Ollero M, Junaidi O, Zaman MM, Tzameli I, Ferrando AA, Andersson C, Blanco PG, Bialecki E, Freedman SD: Decreased expression of peroxisome proliferator activated receptor $\gamma$ in CFTR $^{-/}$mice. J Cell Physiol 2004 200:235-244.

13. Perez A, van Heeckeren AM, Nichols D, Gupta S, Eastman JF, Davis PB: Peroxisome proliferator-activated receptor- $\gamma$ in cystic fibrosis lung epithelium. Am J Physiol Lung Cell Mol Physiol 2008, 295:L303-L313.

14. Sagel S, Kapsner R, Osberg L: Induced sputum matrix metalloproteinase-9 correlates with lung function and airway inflammation in children with cystic fibrosis. Pediatr Pulmonol 2005, 39:224-232

15. Mayer-Hamblett N, Aitken ML, Accurso FJ, Kronmal RA, Konstan MW, Burns JL, Sagel SD, Ramsey BW: Association between pulmonary function and sputum biomarkers in cystic fibrosis. Am J Respir Crit Care Med 2007 175:822-828.

16. Griese $M$, von Bredow C, Birrer P: Reduced proteolysis of surfactant protein A and changes of the bronchoalveolar lavage fluid proteome by inhaled alpha 1-protease inhibitor in cystic fibrosis. Electrophoresis 2001, 22:165-171.

17. Downey D, Martin S, Dempster M, Moore J, Keogan M, Starcher B, Edgar J, Bilton D, Elborn J: The relationship of clinical and inflammatory markers to outcome in stable patients with cystic fibrosis. Pediatr Pulmonol 2007, 42:216-220.

18. Rowe SM, Jackson PL, Liu G, Hardison M, Livraghi A, Solomon GM, McQuaid DB, Noerager BD, Gaggar A, Clancy JP, O’Neal W, Sorscher EJ, Abraham E, Blalock JE: Potential role of high-mobility group box 1 in cystic fibrosis airway disease. Am J Respir Crit Care Med 2008, 178:822-831.

19. Sagel SD, Chmiel JF, Konstan MW: Sputum biomarkers of inflammation in cystic fibrosis lung disease. Proc Am Thorac Soc 2007, 4:406-417.

20. Gharib S, Vaisar T, Aitken M, Park D, Heinecke J, Fu X: Mapping the lung proteome in cystic fibrosis. J Proteome Res 2009, 8:3020-3029.

21. MacGregor G, Gray RD, Hilliard TN, Imrie M, Boyd AC, Alton EWFW, Bush A, Davies JC, Innes JA, Porteous DJ, Greening AP: Biomarkers for cystic fibrosis lung disease: application of SELDI-TOF mass spectrometry to BAL fluid. J Cyst Fibros 2008, 7:352-358.

22. Gray RD, MacGregor G, Noble D, Imrie M, Dewar M, Boyd AC, Innes JA, Porteous DJ, Greening AP: Sputum proteomics in inflammatory and suppurative respiratory diseases. Am J Respir Crit Care Med 2008, 178:444-452.
23. Frischer T, Myung J, Maurer G, Eichler I, Szepfalusi Z, Lubec G: Possible dysregulation of chaperon and metabolic proteins in cystic fibrosis bronchial tissue. Proteomics 2006, 6:3381-3388.

24. Srivastava M, Eidelman O, Jozwik C, Paweletz C, Huang W, Zeitlin PL, Pollard $\mathrm{HB}$ : Serum proteomic signature for cystic fibrosis using an antibody microarray platform. Mol Genet Metab 2006, 87:303-310.

25. Pollard HB, Eidelman O, Jozwik C, Huang W, Srivastava M, Ji XD, McGowan B, Norris CF, Todo T, Darling T, Mogayzel PJ, Zeitlin PL, Wright J, Guggino WB, Metcalf E, Driscoll WJ, Mueller G, Paweletz C, Jacobowitz DM: De novo biosynthetic profiling of high abundance proteins in cystic fibrosis lung epithelial cells. Mol Cell Proteomics 2006, 5:1628-1637.

26. Roxo-Rosa M, da Costa G, Luider T, Scholte B, Coelho A, Amaral M, Penque D: Proteomic analysis of nasal cells from cystic fibrosis patients and noncystic fibrosis control individuals: search for novel biomarkers of cystic fibrosis lung disease. Proteomics 2006, 6:2314-2325.

27. Carvalho-Oliveira I, Charro N, Aarbiou J, Buijs-Offerman R, Wilke M, Schettgen T, Kraus T, Titulaer M, Burgers P, Luider T, Penque D, Scholte B: Proteomic analysis of naphthalene-induced airway epithelial injury and repair in a cystic fibrosis mouse model. J Proteome Res 2009, 8:3606-3616.

28. Brouillard F, Bensalem N, Hinzpeter A, Tondelier D, Trudel S, Gruber AD, Ollero $M$, Edelman A: Blue native/SDS-PAGE analysis reveals reduced expression of the mClCA3 protein in cystic fibrosis knock-out mice. Mol Cell Proteomics 2005, 4:1762-1775

29. Bensalem N, Ventura AP, Vallée B, Lipecka J, Tondelier D, Davezac N, Santos AD, Perretti M, Fajac A, Sermet-Gaudelus I, Renouil M, Lesure J, Halgand F, Laprévote $\mathrm{O}$, Edelman A: Down-regulation of the anti-inflammatory protein annexin $\mathrm{A} 1$ in cystic fibrosis knock-out mice and patients. Mol Cell Proteomics 2005, 4:1591-1601

30. Sloane AJ, Lindner RA, Prasad SS, Sebastian LT, Pedersen SK, Robinson M, Bye PT, Nielson DW, Harry JL: Proteomic analysis of sputum from adults and children with cystic fibrosis and from control subjects. Am J Respir Crit Care Med 2005, 172:1416-1426.

31. McMorran BJ, Ouvry Patat SA, Carlin JB, Grimwood K, Jones A, Armstrong DS, Galati JC, Cooper PJ, Byrnes CA, Francis PW, Robertson CF, Hume DA, Borchers $\mathrm{CH}$, Wainwright $\mathrm{CE}$, Wainwright $\mathrm{BJ}$ : Novel neutrophil-derived proteins in bronchoalveolar lavage fluid indicate an exaggerated inflammatory response in pediatric cystic fibrosis patients. Clin Chem 2007, 53:1782-1791

32. Woods DE, Cantin A, Cooley J, Kenney DM, Remold-O'Donnell E: Aerosol treatment with MNEI suppresses bacterial proliferation in a model of chronic Pseudomonas aeruginosa lung infection. Pediatr Pulmonol 2005, 39:141-149.

33. Roum JH, Buhl R, McElvaney NG, Borok Z, Crystal RG: Systemic deficiency of glutathione in cystic fibrosis. J Appl Physiol 1993, 75:2419-2424.

34. Chen J, Kinter M, Shank S, Cotton C, Kelley T, Ziady A: Dysfunction of Nrf-2 in CF epithelia leads to excess intracellular $\mathrm{H}_{2} \mathrm{O}_{2}$ and inflammatory cytokine production. PLoS One 2008, 3:e3367.

35. Bai Y, Galetskiy D, Damoc E, Paschen C, Liu Z, Griese M, Liu S, Przybylsk M High resolution mass spectrometric alveolar proteomics: identification of surfactant protein SP-A and SP-D modifications in proteinosis and cystic fibrosis patients. Proteomics 2004, 4:2300-2309.

36. Schulz BL, Sloane AJ, Robinson LJ, Prasad SS, Lindner RA, Robinson M, Bye PT, Nielson DW, Harry JL, Packer NH, Karlsson NG: Glycosylation of sputum mucins is altered in cystic fibrosis patients. Glycobiology 2007, 17:698-712.

37. Goldstein RF, Niraj A, Sanderson TP, Wilson LS, Rab A, Kim H, Bebok Z, Collawn JF: VCP/p97 AAA-ATPase does not interact with the endogenous wild-type cystic fibrosis transmembrane conductance regulator. Am J Respir Cell Mol Biol 2007, 36:706-714.

38. Gomes-Alves P, Neves S, Coelho A, Penque D: Low temperature restoring effect on F508del-CFTR misprocessing: a proteomic approach. $J$ Proteomics 2009, 73:218-230.

39. Singh OV, Pollard HB, Zeitlin PL: Chemical rescue of $\triangle$ F508-CFTR mimics genetic repair in cystic fibrosis bronchial epithelial cells. Mol Cell Proteomics 2008, 7:1099-1110.

40. Wang $X$, Venable J, LaPointe $P$, Hutt D, Koulov A, Coppinger J, Gurkan C, Kellner W, Matteson J, Plutner H, Riordan J, Kelly J, Yates J, 3rd, Balch W: Hsp90 cochaperone Aha1 downregulation rescues misfolding of CFTR in cystic fibrosis. Cell 2006, 127:803-815.

41. Thelin W, Che Y, Gentzsch M, Kreda S, Sallee J, Scarlett C, Borchers C, Jacobson K, Stutts M, Milgram S: Direct interaction with filamins modulates the stability and plasma membrane expression of CFTR. J Clin Invest 2007, 117:364-374 
42. Pedersen SK, Sloane AJ, Prasad SS, Sebastian LT, Lindner RA, Hsu M, Robinson M, Bye PT, Weinberger RP, Harry JL: An immunoproteomic approach for identification of clinical biomarkers for monitoring disease. Mol Cell Proteomics 2005, 4:1052-1060.

43. Rao AR, Laxova A, Farrell PM, Barbieri JT: Proteomic identification of OprL as a seromarker for initial diagnosis of Pseudomonas aeruginosa infection of patients with cystic fibrosis. J Clin Microbiol 2009, 47:2483-2488.

44. Montor WR, Huang J, Hu Y, Hainsworth E, Lynch S, Kronish J, Ordonez CL, Logvinenko T, Lory S, LaBaer J: Genome-wide study of Pseudomonas aeruginosa outer membrane protein immunogenicity using selfassembling protein microarrays. Infect Immun 2009, 77:4877-4886.

45. Vanlaere E, Sergeant K, Dawyndt P, Kallow W, Erhard M, Sutton H, Dare D, Devreese B, Samyn B, Vandamme P: Matrix-assisted laser desorption ionisation-time-of-flight mass spectrometry of intact cells allows rapid identification of Burkholderia cepacia complex. J Microbiol Methods 2008, 75:279-286

46. Sriramulu D, Nimtz M, Romling U: Proteome analysis reveals adaptation of Pseudomonas aeruginosa to the cystic fibrosis lung environment. Proteomics 2005, 5:3712-3721.

47. Malhotra S, Silo-Suh LA, Mathee K, Ohman DE: Proteome analysis of the effect of mucoid conversion on global protein expression in Pseudomonas aeruginosa strain PAO1 shows induction of the disulfide bond isomerase DsbA. J Bacterio/ 2000, 182:6999-7006.

48. Platt MD, Schurr MJ, Sauer K, Vazquez G, Kukavica-Ibrulj I, Potvin E, Levesque RC, Fedynak A, Brinkman FSL, Schurr J, Hwang S, Lau GW, Limbach PA, Rowe J, Lieberman MA, Barraud N, Webb J, Kjelleberg S, Hunt DF, Hassett DJ: Proteomic, microarray, and signature-tagged mutagenesis analyses of anaerobic Pseudomonas aeruginosa at pH 6.5, likely representing chronic, late-stage cystic fibrosis airway conditions. J Bacterio/ 2008, 190:2739-2758.

49. Guina T, Purvine SO, Yi EC, Eng J, Goodlett Dr, Aebersold R: Quantitative proteomic analysis indicates increased synthesis of a quinolone by Pseudomonas aeruginosa isolates from cystic fibrosis airways. Proc Natl Acad Sci U S A 2003, 100:2771-2776.

50. Courtney J, Bradley J, McCaughan J, O'Connor T, Shortt C, Bredin C, Bradbury I, Elborn J: Predictors of mortality in adults with cystic fibrosis. Pediatr Pulmonol 2007, 42:525-532.
51. Arevalo-Ferro C, Hentzer M, Reil G, Görg A, Kjelleberg S, Givskov M, Riedel K, Eberl L: Identification of quorum-sensing regulated proteins in the opportunistic pathogen Pseudomonas aeruginosa by proteomics. Environ Microbiol 2003, 5:1350-1369.

52. Riedel K, Arevalo-Ferro C, Reil G, Görg A, Lottspeich F, Eberl L: Analysis of the quorum-sensing regulon of the opportunistic pathogen Burkholderia cepacia $\mathrm{H} 111$ by proteomics. Electrophoresis 2003, 24:740-750.

53. Guo Y, Ma S, Grigoryev D, Van Eyk J, Garcia J: 1-DE MS and 2-D LC-MS analysis of the mouse bronchoalveolar lavage proteome. Proteomics 2005 5:4608-4624.

54. Welsh M, Rogers C, Stoltz D, Meyerholz D, Prather R: Development of a porcine model of cystic fibrosis. Trans Am Clin Climatol Assoc 2009, 120:149-162.

55. Stoltz DA, Meyerholz DK, Pezzulo AA, Ramachandran S, Rogan MP, Davis GJ, Hanfland RA, Wohlford-Lenane C, Dohrn CL, Bartlett JA, Nelson GA, Chang EH, Taft PJ, Ludwig PS, Estin M, Hornick EE, Launspach JL, Samuel M, Rokhlina T, Karp PH, Ostedgaard LS, Uc A, Starner TD, Horswill AR, Brogden KA, Prather RS, Richter SS, Shilyansky J, McCray PB, Zabner J, Welsh MJ: Cystic fibrosis pigs develop lung disease and exhibit defective bacterial eradication at birth. Sci Trans/ Med 2010, 2:29ra31-29ra31.

56. Kitteringham NR, Jenkins RE, Lane CS, Elliott VL, Park BK: Multiple reaction monitoring for quantitative biomarker analysis in proteomics and metabolomics. J Chromatogr B Analyt Technol Biomed Life Sci 2009, 877:1229-1239.

57. Makawita S, Diamandis EP: The bottleneck in the cancer biomarker pipeline and protein quantification through mass spectrometry-based approaches: current strategies for candidate verification. Clin Chem 2010, 56:212-222.

58. Ramsey BW: Outcome measures for development of new therapies in cystic fibrosis: are we making progress and what are the next steps? Proc Am Thorac Soc 2007, 4:367-369.

doi:10.1186/gm209

Cite this article as: Pattison SH, Elborn JS: Protein biomarkers in cystic fibrosis research: where next? Genome Medicine 2010, 2:88. 